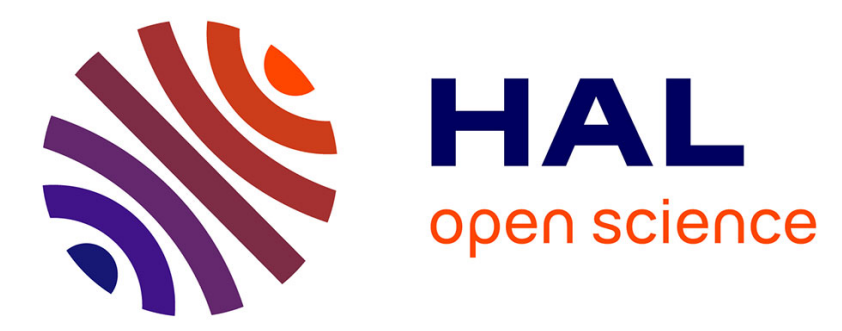

\title{
Agriculture erases climate constraints on soil nematode communities across large spatial scales
}

Xianping Li, Huimin Zhu, Stefan Geisen, Céline A Bellard, Feng Hu, Huixin

Li, Xiaoyun Chen, Manqiang Liu

\section{- To cite this version:}

Xianping Li, Huimin Zhu, Stefan Geisen, Céline A Bellard, Feng Hu, et al.. Agriculture erases climate constraints on soil nematode communities across large spatial scales. Global Change Biology, 2019, 26 (2), pp.919 - 930. 10.1111/gcb.14821 . hal-03252157

\section{HAL Id: hal-03252157 \\ https://hal.science/hal-03252157}

Submitted on 7 Jun 2021

HAL is a multi-disciplinary open access archive for the deposit and dissemination of scientific research documents, whether they are published or not. The documents may come from teaching and research institutions in France or abroad, or from public or private research centers.
L'archive ouverte pluridisciplinaire HAL, est destinée au dépôt et à la diffusion de documents scientifiques de niveau recherche, publiés ou non, émanant des établissements d'enseignement et de recherche français ou étrangers, des laboratoires publics ou privés. 



\title{
Agriculture erases climate constraints on soil nematodecommunities across large spatial scales
}

\author{
Xianping $\mathrm{Li}^{1} \quad$ Huimin Zhu ${ }^{1} \quad$ Stefan Geisen $^{2} \quad$ Céline Bellard ${ }^{3}$ Feng $\mathrm{Hu}^{1,4}$ । \\ Huixin $\mathrm{Li}^{1,4} \quad$ Xiaoyun Chen ${ }^{1,4} \quad$ Manqiang Liu, \\ ${ }^{1}$ Soil Ecology Lab, College of Resources \\ and Environmental Sciences, Nanjing Agricultural University, Nanjing, China \\ ${ }^{2}$ Department of Terrestrial Ecology, Netherlands Institute of Ecology (NIOO- KNAW), Wageningen, The Netherlands \\ ${ }^{3}$ Laboratoire Ecologie, Systématique \& Evolution, UMR8079, Université Paris- Sud,Orsay, France \\ ${ }^{4}$ Jiangsu Collaborative Innovation Center for Solid Organic Waste Resource Utilization, Jiangsu Key Laboratory for SolidOrganic Waste Utilization, Nanjing, China
}

\section{Correspondence}

Manqiang Liu, Soil Ecology Lab, College ofResources and Environmental Sciences, Nanjing Agricultural University, Nanjing, China.

Email: liumq@njau.edu.cn

\section{Funding information}

Special Fund for Agro- scientific Research in the Public Interest, Grant/Award Number: 201503121; Fundamental Research Funds for the Central Universities, Grant/Award Number: KYYJ201702; China Agriculture Research System- Green Manure, Grant/ Award Number: CARS- 22- G- 10; National Key R\&D Program of China, Grant/Award Number: 2016YFD0200305; Netherlands Organisation for Scientific Research, Grant/ Award Number: 016.Veni.181.078; National Natural Science Foundation of China, Grant/ Award Number: 41877056 


\begin{abstract}
:
Anthropogenic conversion of natural to agricultural land reduces aboveground biodiversity. Yet, the overall consequences of land- use changes on belowground biodiversity at large scales remain insufficiently explored. Furthermore, the effects of conversion on different organism groups are usually determined at the taxonomic level, while an integrated investigation that includes functional and phylogenetic levels is rare and absent for belowground organisms. Here, we studied the Earth's most abundant metazoa — nematodes — to examine the effects of conversion from natural to agricultural habitats on soil biodiversity across a large spatial scale. To this aim, we investigated the diversity and composition of nematode communities at the taxonomic, functional, and phylogenetic level in 16 assemblage pairs(32 sites in total with 16 in each habitat type) in mainland China. While the overall alpha and beta diversity did not differ between natural and agricultural systems, all three alpha diversity facets decreased with latitude in natural habitats. Both alpha and beta diversity levels were driven by climatic differences in natural habitats, while none of the diversity levels changed in agricultural systems. This indicates that land conversion affects soil biodiversity in a geographically dependent manner and that agriculture could erase climatic constraints on soil biodiversity at such a scale. Additionally, the functional composition of nematode communities was more dissimilar in agricultural than in natural habitats, while the phylogenetic composition was more similar, indicating that changes among different biodiversity facets are asynchronous. Our study deepens the understanding of land- use effects on soil nematode diversity across large spatial scales. Moreover, the detected asynchrony of taxonomic, functional, and phylogenetic diversity highlights the necessity to monitor multiple facets of soil biodiversity in ecological studies such as those investigating environmental changes.
\end{abstract}


To meet increasing food demands, a large number of natural systems is being converted to agricultural ecosystems at a global scale (Tilman, Balzer, Hill, \& Befort, 2011). Conversion of natural to agricultural ecosystems was shown to reduce the biodiversity of insects, plants, birds, and mammals at both local and regional scales, and to homogenize biological communities across space (Flynn et al., 2009; Gossner et al., 2016; Karp et al., 2012; Ponisio, M'Gonigle, \& Kremen, 2016; Solar et al., 2015). Ultimately, these losses might negatively affect ecosystem services and human well- being (Díaz, Fargione, Chapin, \& Tilman, 2006). To efficiently conserve biological diversity and maintain ecosystem functions, it is crucial to monitor diversity changes and investigate the underlying processes relating to land- use changes.

As an essential component of global biodiversity, soil biota (including animals and microbes) contribute to the provisioning of several ecosystem services (Bardgett \& van der Putten, 2014; van den Hoogen et al., 2019; Wardle et al., 2004). Nematodes are among the most diverse, abundant, and widespread metazoa on Earth. Being distributed in multiple trophic levels in the soil food web, nematodes participate in diverse ecological processes like the decomposition of organic material and the mineralization of nutrients in soils (Bongers \& Ferris, 1999; Yeates, 2003). Nematodes respond quickly and in a taxon-specific manner to environmental changes, and as a result, they are valuable bioindicators (Bongers \& Ferris, 1999; Chen, Daniell, Neilson, O'Flaherty, \& Griffiths, 2010; Yeates, 2003). For instance, opportunistic nematodes with a short generation time, small body size, and/or high fecundity-often bacterivores-respond positively to disturbance, while taxa with a longer generation time, larger body size, and/or lower fecundity-often omnivores and predatorsare sensitive to disturbance (Bongers \& Ferris, 1999; Ferris, Bongers, \& de Goede, 2001; Liu, Guo, Ran, Whalen, \& Li, 2015). This suggests that functional composition might change following land conversion regardless of taxonomic changes. Numerous studies have assessed the effects of land-use intensification on soil biodiversity with a focus on nematodes in agricultural habitats at local and regional scales (Freckman \& Ettema, 1993; Neher, 2010; Postma- Blaauw, de Goede, Bloem, Faber, \& Brussaard, 2010). Nevertheless, the largescale patterns and processes determining nematode diversity have only been investigated in a few studies to date (Decaëns, 2010; Nielsen et al., 2014; Wu, Ayres, Bardgett, Wall, \& Garey, 2011). This prevents us from fully understanding how nematode communities are structured according to different land-use types. Moreover, these studies mostly focus on a particular facet of diversity (e.g., species richness), which might undermine other important changes induced by land conversion (e.g., changes in functional or phylogenetic composition) that affect soil nematodes.

Diversity is a key measurement describing communities, which can be defined in different ways. Alpha diversity refers to the diversity in a specific area (generally at a local scale) and can be defined as taxonomic (TD), functional (FD), and phylogenetic diversity (PD). Each of these biodiversity facets provides distinct information about the impacts of different abiotic and biotic factors on biodiversity across time and space, thereby enabling better predictions of poten- tial consequences of biodiversity change (Jarzyna \& Jetz, 2016). For example, TD can inform whether and how TD (e.g., taxon richness) changes in response to the gains or losses of taxa. FD describes the functional differences among taxa in a community, which can be used to examine whether a community can maintain its functions under environmental changes (Petchey \& Gaston, 2002). PD incor- porates the phylogenetic difference between taxa, which is useful for evaluating the potential features of taxa to adapt in changing environments, as it is based on evolutionary relationships between taxa (Faith, 1992; Winter, Devictor, \& Schweiger, 2013). Compared to TD, both FD and PD have only recently been included in soil nem- atode research ( $\mathrm{Li}$ et al., 2014; Mulder \& Maas, 2017), despite that they might help in understanding potential consequences of land conversion.

In contrast to these alpha diversity measurements focusing on single- site metrics, beta diversity compares the community composition among sites and provides complementary information about taxon turnover (McGill, Dornelas, Gotelli, \& Magurran, 2015). For instance, it is possible to investigate whether the original community distinctiveness is lost (i.e., increased community similarity) under environmental changes by assessing changes in taxonomic $(\beta T D)$, functional $(\beta F D)$, or phylogenetic beta diversity ( $\beta P D ;$ Graham \& Fine, 2008; Swenson, 2011; Whittaker, 1972). In other words, it allows us to decipher the difference between current similarity (e.g., community similarity after land conversion) and initial similarity (e.g., community similarity before land conversion). Understanding these changes is important for monitoring and maintaining diversity and ecosystem functions in response to future land-use change (Mori, Isbell, \& Seidl, 2018; Socolar, Gilroy, Kunin, \& Edwards, 2016). To date, the generally negative effects (diversity loss and biotic homog- enization) of land- use intensification on biodiversity have been doc- umented across taxonomic (Gossner et al., 2016; Karp et al., 2012; Solar et al., 2015), functional (Devictor et al., 2008; Flynn et al., 2009; Karp et al., 2012), and phylogenetic facets of diversity (Frishkoff et al., 2014; Nowakowski, Frishkoff, Thompson, Smith, \& Todd, 2018; Sol, Bartomeus, González-Lagos, \& Pavoine, 2017). However, most of these studies focus on aboveground organisms, including insects, plants, birds, and mammals (Flynn et al., 2009; Gossner et al., 2016; Karp et al., 2012; Ponisio et al., 2016; Solar et al., 2015). To our knowl- edge, no study to date has assessed the effects of land conversion on both alpha and beta diversity of soil fauna (e.g., nematodes) in terms of taxonomic, functional, and phylogenetic aspects.

To determine the effects of habitat conversion (from natural habitats to agriculture) on soil biodiversity at a large spatial scale, we obtained soil samples from 32 paired sites across mainland Chinafrom different climatic conditions. We then calculated the TD, FD, and PD of nematode communities using incidence- based data (i.e., any nematode taxon in a community with a population size greater than zero is treated as presence; otherwise absence) at both alpha and beta diversity levels. We used incidence-based data to avoid the intractable nematode population dynamics that are mediated by 

local microhabitats (Paul, 2015) and to be comparable with diversity patterns in aboveground animal groups for which presence-absence data are widely used for analyzing large- scale patterns (Flynn et al., 2009). We also examined the potential drivers (e.g., climatic and soil parameters) associated with these biodiversity patterns. We hypothesized that (a) land conversion reduces the TD of soil nematodes and promotes the homogenization of nematode communities (decrease in $\beta T D)$, since homogeneous agricultural landscapes have been shown to support lower diverse communities (Flynn et al., 2009; Gossner et al., 2016; Karp et al., 2012); (b) agricultural activities do not affect the FD and $\beta F D$ of nematode communities because of a high functional redundancy among nematode taxa (Bongers \& Bongers, 1998; Ferris et al., 2001); and (c) PD and $\beta$ PD show similar changes to FD and $\beta F D$, because taxa with similar functional traits may share a similar evolutionary history (Blomberg \& Garland, 2002).

\section{2 | MATERIALS AND METHODS}

\subsection{Soil sampling and nematode identification}

Consistent with previous studies, we used a space-for-time substitu- tion approach to examine the effects of land- use changes on soil biodiversity (Karp et al., 2012; Pickett, 1989). Briefly, we obtained soil samples from 16 pairs of agricultural fields with a nearby nat- ural habitat and covering a broad spatial range in mainland China (Figure S1). Here, we focused our site selection on agricultural fieldsin upland double-cropping areas, as they represent more than $60 \%$ of arable upland systems and provide food for nearly $50 \%$ of the Chinese population (Li et al., 2017, 2019). Yet the broad patterns and processes of soil diversity (e.g., nematode diversity) in these soil systems are still unclear. Furthermore, as arable upland systems are sensitive to environmental changes at a global level (Montgomery, 2007), understanding the distribution of soil biota and their response to environmental changes (e.g., land conversion) is essential to opti- mize further soil management. From these systems, we standardized our site selection by focusing on maize planting areas. Maize is the most commonly grown second crop in annual rotations, and it cov- ers a large area of mainland China (Meng, Hu, Shi, \& Zhang, 2006). We selected the field sites by maximizing the geographical gradient, avoiding large and industrialized cities with high levels of additional anthropogenic disturbance, and considering the accessibility and af- fordability of sampling sites. This conservative selection yielded 16 highly comparable sites, which had been in place for at least 20 years (induced by the reduction of cropping areas in the Grain for Green Project in 1999). These agricultural sites are located in flat areas and are managed conventionally. Low agricultural income combined with limited manpower for land management results in the reduced application of fertilizers, pesticides, and other inputs. Despite the lack of detailed information on agricultural practices, the measured soil properties mentioned below could reflect the effects of these practices on soil. Correspondingly, we defined the nearby natural communities as those that were largely unaffected by agricultural activity, mainly shrublands and woodlands near the agricultural fields (Figure S2). Within each site, three plots (about $20 \mathrm{~m}^{2}$ ), situated at least $100 \mathrm{~m}$ from each other, were randomly selected. After removing litter, roots, and rocks, five soil cores with a diameter of $3.5 \mathrm{~cm}$ and a depth of $0-10 \mathrm{~cm}$ were randomly collected and mixed for each plot. In total, 96 soil samples were collected from August to October 2016 during the maize harvest to minimize the effects of agricultural management, including fertilization, tillage, and pesticide application. Nematodes were extracted from $100 \mathrm{~g}$ fresh soil using a modified Baermann method followed by sugar centrifugal flotation (Liu et al., 2008). This method has the advantage of obtaining comprehensive information on the whole nematode community, while being less labor consuming than the traditional Baermann funnel and centrifugation methods (Liu et al., 2008). After counting the total number of nematodes, about 150 randomly chosen individuals from each soil sample were identified to genus with a light microscope (Olympus) at 400× magnification (Bongers \& Bongers, 1998; Liu et al., 2015), which result in a total of about 14,400 individuals identified. All plots were measured separately, and values were averaged to represent site conditions of natural and agricultural habitats separately.

\subsection{Soil and climate attributes}

After drying and sieving soil samples, we measured several key soil physicochemical properties for all samples. Soil organic carbon (SOC; $\mathrm{g} / \mathrm{kg}$ ) and total nitrogen ( $\mathrm{TN} ; \mathrm{g} / \mathrm{kg}$ ) were analyzed using a $\mathrm{C} / \mathrm{N}$ analyzer (Elementar Co.; Nielsen et al., 2014; Wu et al., 2011). Soil $\mathrm{pH}$ was measured using a soil water suspension (1:2.5 weight/ volume) with a pH meter (Hanna; Delgado- Baquerizo et al., 2018). Percentages of clay, silt, and sand were estimated after sieving by granulometric analysis (Gee \& Or, 2002). For each site, we also extracted four climate variables, that is, the mean values of annual temperature $\left({ }^{\circ} \mathrm{C}\right)$, annual precipitation $(\mathrm{mm})$, temperature seasonality, and precipitation seasonality, from WorldClim (http://www.world clim.org/) at a resolution of 30 arc-seconds (approximately $1 \mathrm{~km}$ at the equator). All these variables have been documented as potential determinants of the diversity and composition of above- and belowground organisms (Decaëns, 2010; Hawkins et al., 2003; Nielsen et al., 2014; Wu et al., 2011).

\section{3 | Functional traits}

We used three trait categories to describe the functional characterization of the nematodes: (a) diet: bacterivore, fungivore, herbivore, omnivore, and predator (Neher, Peck, Rawlings, \& Campbell, 1995; Yeates, Bongers, de Goede, Freckman, \& Georgieva, 1993); (b) c- $p$ value (colonizer-persister): ranges from 1 to 5 , representing the position of the taxon on a $r-K$ spectrum, with higher $c-p$ groups being more susceptible to environmental disturbance and change (Bongers \& Bongers, 1998; Bongers \& Ferris, 1999); and (c) body mass ( $\mu \mathrm{g})$ : the mass averaged across species in a given genus. These traits are critical for nematodes to perform a variety of functions (e.g., soil nutrient cycling) within ecosystems, since taxa with different functional 
traits may respond to local resources and environmental stressors differently (Bongers \& Bongers, 1998; Ferris, 2010; Yeates, 2003). Although other indices such as structure index and metabolic footprint (Ferris, 2010; Ferris et al., 2001) can be used to describe the physiological and ecological characteristics of nematodes, these are mainly calculated from the abovementioned traits using empirical formulas. For this reason, they were not considered in this study. We obtained these traits from the database of Nematode Ecophysiological Parameter (http://nemaplex.ucdavis.edu). The associations between these functional traits and the abovementioned environmental variables were assessed with fourth-corner analysis for natural and agricultural habitats separately. The fourth-corner method analyzes the associations through the link of three matrices of environmental data, presence-absence data, and taxon trait data (Dray \& Legendre, 2008; Legendre, Galzin, \& Harmelin- Vivien, 1997). A sequential approach with models 2 and 4 and 999 permutations was used to evaluate the significance of these associations (Dray \& Legendre, 2008).

\section{4 | Phylogeny}

Unlike many aboveground taxa, the genetic analysis of soil fauna is still at its infancy. Despite the availability of a substantial amount of gene sequences (e.g., 18S rRNA) for soil nematodes, which can infer their phylogenetic relationships, PD for soil nematodes has been infrequently used to date (Floyd, Abebe, Papert, \& Blaxter, 2002; Geisen et al., 2018). Thus, we acknowledge that more studies using PD are required to confirm the ecological relevance of this metric. Here, we built a phylogenetic tree of all genera identified in the current study from the Open Tree of Life (OTL) using the rotl $\mathrm{R}$ package v.3.0.4 (Michonneau, Brown, \& Winter, 2016). As the most comprehensive tree of life, OTL assembles both the global reference taxonomy and the database of published phylogenies mapped to this taxonomy, which provides up- to- date phylogenetic information for fundamental biodiversity research and relevant applications (Hinchliff et al., 2015). Because the branch lengths of these nematodes are unknown, they were computed based on Grafen's method (1989) after resolving multichotomies using the ape package v.5.2 (Paradis, Claude, \& Strimmer, 2004), whereby each node is given a branch length equal to the number of descendant tips minus one (Figure S3).

\section{5 | Alpha and beta diversity index}

Many different metrics can be used to measure FD, each with different advantages and disadvantages (Mouchet, Villéger, Mason, \& Mouillot, 2010; Petchey \& Gaston, 2002; Schleuter, Daufresne, Massol, \& Argillier, 2010; Villéger, Mason, \& Mouillot, 2008). To be comparable with the PD metrics, which are generally calculated on phylogenetic trees, we adopted a dendrogram-based approach to measure FD. To create a trait dendrogram, we calculated a distance matrix (functional dissimilarity) by using the functional traits to compute the distances between taxon pairs, while Gower's distance was used to measure the interspecific dissimilarity, because some traits are qualitative. The matrix was then constructed into a hierarchical dendrogram using an unweighted pair group method with arithmetic mean clustering method (Jarzyna \& Jetz, 2017; Podani \& Schmera, 2006; Figure S4). Body mass was log-transformed before building the functional tree.

For alpha diversity, TD was assessed using the number of genera within a community. FD and PD were respectively measured as the sum of the total branch lengths of the functional and phylogenetic trees connecting all genera in a community (Faith's index; Faith, 1992; Petchey \& Gaston, 2002). To assess whether the chosen sample size for nematode identification (i.e., 150 individuals per sample) will affect the measurements of multifaceted diversity, we rarefied 150 individuals from each site for 999 times to obtain the expected values of TD, FD, and PD. Thereafter, we calculated the correlations between the observed values and the medians of these expected values. Extremely high correlation coefficients were found for all three diversity metrics (all $r>.89$, all $p<.001$; Table S1). This indicates that the identification of 150 individuals is a good representation of the total nematode community composition. For beta diversity, the Sørensen's index was used to calculate the $\beta$ TD for each paired assemblage (Baselga, 2010). PhyloSor index, a derivative of Sørensen's index, which considers both shared and total breach lengths between communities, was used to calculate $\beta \mathrm{FD}$ and $\beta \mathrm{PD}$ (Bryant et al., 2008).

\subsection{Significance of changes and congruence between facets}

The differences in the taxonomic, functional, and phylogenetic diver- sities (alpha diversity) between natural and agricultural communities were tested using the Wilcoxon signed-rank test. Analysis of simi- larities (ANOSIM) with 999 permutations was used to test whether taxonomic, functional, and phylogenetic community compositions (beta diversity) differed between natural and agricultural sites (Clarke, 1993). The dissimilarities between communities were visual- ized with nonmetric multidimensional scaling. Pearson's correlation coefficients were used to measure the correlations between TD, FD, and PD. Correlations in $\beta T D, \beta F D$, and $\beta P D$ were examined using the Mantel tests based on 999 permutations (Goslee \& Urban, 2007). To assess the congruence between changes in taxonomic, functional, and phylogenetic aspects at both alpha and beta diversity levels, we used a permutation procedure with 999 iterations to test the differ- ence in slopes between the regression line of any two changes and the 1:1 line. In addition, we disentangled the cross- associations of changes in TD, FD, and PD ([agricultural diversity - natural diver- sity]/natural diversity) or similarity (agricultural similarity - natural similarity) into different scenarios to gain a better understanding of the underlying processes of biodiversity changes (Figure 1; Baiser \& Lockwood, 2011; Jarzyna \& Jetz, 2017). For example, a larger in- crease in TD compared to the increase in FD (or PD) could come froma gain in functionally (or phylogenetically) redundant taxa (Figure 1a, region II); while a larger increase in FD (or PD) could be explained by 

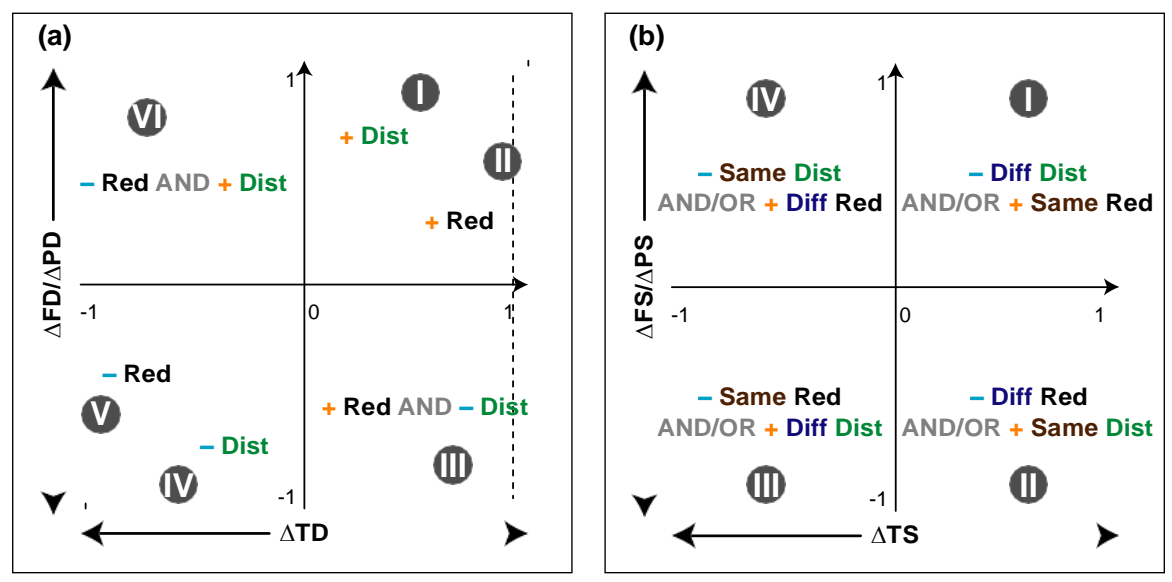

F I G U R E 1 Conceptual diagram of the relationship between changes in taxonomic diversity ( $\Delta \mathrm{TD})$ and changes in functional $(\Delta \mathrm{FD})$ or phylogenetic diversity $(\triangle \mathrm{PD})(\mathrm{a})$, and the relationship between changes in taxonomic similarity $(\Delta \mathrm{TS})$ and changes in functional $(\Delta \mathrm{FS})$ or phylogenetic similarity $(\triangle \mathrm{PS})(\mathrm{b}) .+$ and - indicate gains and losses of taxa; Red and Dist indicate functionally or phylogenetically redundant and distinct taxa; Same and Diff indicate same and different taxa, respectively. Panel (a) is adapted from figure 1 in Jarzyna and Jetz (2017), and panel (b) from figure 1 in Baiser and Lockwood (2011) [Colour figure can be viewed at wileyonlinelibrary.com]

a gain in functionally (or phylogenetically) distinct taxa (Figure 1a, region I; Jarzyna \& Jetz, 2017). A similar magnitude of increase for both taxonomic and functional (or phylogenetic) similarities indicates that taxa contribute equally to traits diversity (or evolutionary history; Figure 1b, region I; Baiser \& Lockwood, 2011).

\subsection{Assessing the drivers of diversity and composition}

To identify the potential drivers of the multiple facets of soil nematode diversity, we used different approaches for alpha and beta diversity metrics. For alpha diversity, we used univariate linear regression analysis to test the effect of latitude as well as the climate and soil predictors on TD, FD, and PD. Spatial autocorrelation (i.e., proximate sites show similar values than distant sites) could bias our modeling results, because the residuals of the statistical models might not be independent from each other (Dormann et al., 2007). Thus, we tested spatial autocorrelation in the residuals of these models using Moran's I statistic (999 permutations; Bivand, Pebesma, \& Gomez-Rubio, 2013). If spatial autocorrelation was found, then the spatial simultaneous autoregressive error model (SAR), which treats the autocorrelation by incorporating spatial dependence into the error term, was used to investigate the effect of the given variable on diversity (Dormann et al., 2007). A spatial distance weights matrix based on the minimum distance linking each site to at least one other site was used to define the spatial dependence. Due to the high levels of multicollinearity among these climate or soil variables (Figure S5), and the small sample size, we did not conduct further multiple linear regression models to examine the effects of climate and soil together.

To evaluate the effects of spatial distance, climate, and soil conditions on $\beta T D, \beta F D$, and $\beta P D$, we first calculated the climate and soil differences between sites using Euclidean distance on all the principal components obtained from the principal component analyses
(PCA) for the climate and soil variables separately (Figure S6). Spatial distance $(\mathrm{km})$ was calculated based on the coordinates of the sampling sites. Multiple regression on distance matrices (MRM) was used to examine the relationships between the predictor matrices (spatial distance, climate, and soil differences) and three beta diversity metrics ( $\beta T D, \beta F D$, and $\beta P D ;$ Lichstein, 2007). The significance of all regression coefficients was determined using a permutation test $(n=999)$.

Unlike climate condition and spatial location, which were almost consistent for a matched pair of natural and agricultural habitats, differences in soil abiotic parameters within each pair may be larger than the difference between isolated pairs. However, we found that all soil attributes were not significantly different between paired natural and agricultural habitats (Table S2). Each attribute in both habitats generally showed similar trends with latitude (except for SOC, which exhibited a significant latitudinal trend in natural but not agricultural soils; Figure S7). Thus, for each soil attribute, we used the mean value of the two habitats to represent the condition of the site pair. In addition, another PCA was conducted for these mean soil variables (Figure S6), and the Euclidean distances on the transformed principal component axes were used to represent the soil differences between site pairs. We then adopted the MRM models with 999 permutations to assess the effects of initial similarity (similarity in natural habitats), spatial distance, as well as climate and soil differences on the changes in taxonomic, functional, and phylogenetic similarity. All analyses were conducted using R 3.3.0 (R Core Team, 2016).

\section{3 | RESULTS}

\section{1 | Alpha diversity and associated drivers}

In total, we collected 86,365 individuals in 67 nematode genera from all the samples. The mean number of genera was $30.0 \pm 1.7$ 
(mean $\pm S E$ ) in natural habitats, which was not significantly higher than the mean number of $28.1( \pm 1.9)$ in agricultural habitats (Wilcoxon signed- rank test $p=.452$ ). There were also no significant differences between natural and agricultural habitats in FD $(2.4 \pm 0.1$ vs. $2.2 \pm 0.1)$ and PD $(6.9 \pm 0.3$ vs. $6.7 \pm 0.3$; Wilcoxon signed-rank test $p=.105$ and .782 , respectively), neither in the variance among natural versus agricultural habitats (Levene's test, $p>.05$ for all alpha diversity metrics). We also found that TD, FD, and PD were positively correlated with each other in both natural and agricultural habitats (Pearson $r>.90$; all $p<.001$; Table S3). Furthermore, the results of the fourthcorner analysis suggested that the functional traits (i.e., diet and $c-p$ value) mainly vary along environmental gradients in natural systems (Figure S8).

The latitudinal trends of these diversity indices varied between natural and agricultural habitats (Figure 2). All diversity metrics declined with increasing latitude in natural habitats (Pearson $r=-.64$,
-0.70 , and -0.59 for TD, FD, and PD, respectively; $p<.01$ for TD and $\mathrm{FD}, p<.05$ for $\mathrm{PD}$ ), but remained constant in agricultural habitats (Pearson $r$ : TD: 0.15; FD: 0.12; PD: 0.00; all $p>.05$; Figure 2). In natural habitats, the univariate linear regression models showed that all three facets of diversity were positively associated with annual mean temperature (Pearson $r$ : TD: 0.75; FD: 0.77; PD: 0.60; $p<.001$ for TD and FD, $p<.05$ for PD) but negatively correlated with temperature variation (Pearson $r$ : TD: -0.65 ; FD: -0.65 ; PD: $-0.60 ; p<.01$ for TD and FD, $p<.05$ for PD). FD and PD were negatively affected by soil $\mathrm{pH}$ (Pearson $r=-.56$ and -.58 , respectively; all $p<.05$ ) but with TD marginally affected (Pearson $r=-.49 ; p=.054$ ) in natural habitats (Table S4). However, no significant determinants were observed in agricultural habitats (Table S4). Moran's I statistics showed no spatial autocorrelation in the residuals of the linear regression models for most variables, except for precipitation seasonality as well as clay and sand content for TD and FD in natural soils (Table S4). However, further SAR models suggested that these
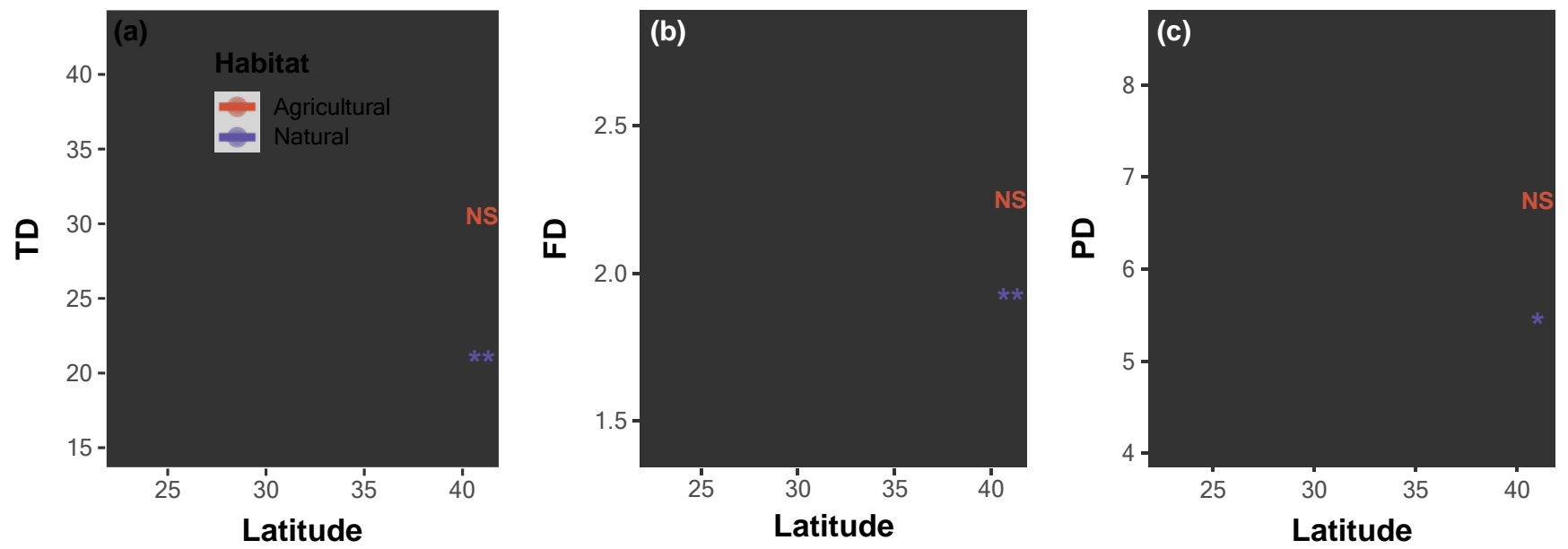

F I G U R E 2 Patterns in the variation of taxonomic (TD; a), functional (FD; b), and phylogenetic (PD; c) alpha diversity along latitude. The colored lines depict linear relationships between diversity and latitude for natural and agricultural habitats. The significance of the slope of the regression line is indicated at the end of the line $\left({ }^{*} p<.05 ;{ }^{*} p<.01 ; \mathrm{NS}\right.$, not significant). Significant models explain $41 \%$, $49 \%$, and $36 \%$ of the observed variation in TD, FD, and PD, respectively [Colour figure can be viewed at wileyonlinelibrary.com]
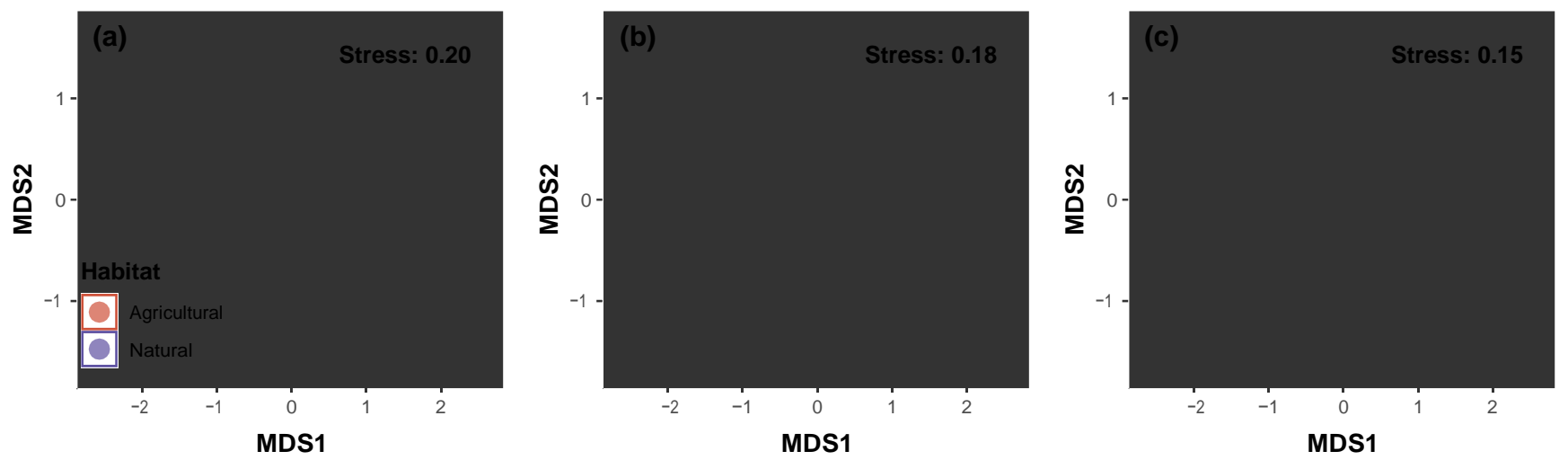

F I G U R E 3 Nonmetric multidimensional scaling plots for the taxonomic (a), functional (b), and phylogenetic (c) composition of soil nematode communities in natural and agricultural habitats. Sørensen's index was used to calculate taxonomic beta diversity, while PhyloSor index was used to calculate functional and phylogenetic beta diversity. Stress values indicate the goodness- of- fit measures for observations in nonmetric multidimensional scaling. Lower values correspond with a better model fit [Colour figure can be viewed at wileyonlinelibrary.com] 
variables were not supported when the spatial autocorrelation was accounted for (Table S4).

\section{2 | Beta diversity and associated drivers}

The taxonomic, functional, and phylogenetic structures of nematode communities were not different between natural and agricultural habitats (ANOSIM's R: $\beta$ TD: 0.026; $\beta \mathrm{FD}: 0.057 ; \beta \mathrm{PD}$ : 0.034; all $p>.05$; Figure 3 ). $\beta \mathrm{TD}, \beta \mathrm{FD}$, and $\beta \mathrm{PD}$ were positively correlated with each other in both natural and agricultural habitats (Mantel $r>.58$; all $p<.001$; Table S5).

The outputs of the MRM models demonstrate that the spatial distance and differences in soil attributes had no effects on $\beta T D, \beta F D$, and $\beta P D$ for the two habitat types (Table 1). Climatic differences on
TA B LE 1 Results of the MRM models testing the effects of spatial distance as well as climatic and soil condition on taxonomic ( $\beta T D)$, functional $(\beta F D)$, or phylogenetic ( $\beta P D)$ beta diversity in natural and agricultural habitats

\begin{tabular}{|ccccc|}
\hline & Spatial distance & Climate condition & Soil condition & $R^{2}$ \\
\hline Natural & & & & \\
\hline$\beta T D$ & $0.000(0.303)$ & $\mathbf{0 . 0 3 6 ( 0 . 0 2 0 )}$ & $0.009(0.468)$ & 0.161 \\
\hline$\beta F D$ & $0.000(0.387)$ & $\mathbf{0 . 0 2 4}(\mathbf{0 . 0 0 4 )}$ & $-0.003(0.611)$ & 0.194 \\
\hline$\beta P D$ & $0.000(0.401)$ & $\mathbf{0 . 0 2 2 ( 0 . 0 3 9 )}$ & $0.001(0.892)$ & 0.095 \\
\hline Agricultura I & & & & \\
\hline$\beta T D$ & $0.000(0.488)$ & $0.005(0.555)$ & $0.007(0.474)$ & 0.017 \\
\hline$\beta F D$ & $0.000(0.507)$ & $0.000(0.993)$ & $-0.002(0.767)$ & 0.013 \\
\hline$\beta P D$ & $0.000(0.095)$ & $-0.003(0.715)$ & $0.004(0.595)$ & 0.050 \\
\hline
\end{tabular}

Note: The significance shown in parentheses was calculated based on 999 permutations for each predictor, with the significant predictors being shown in bold $(p<.05)$.
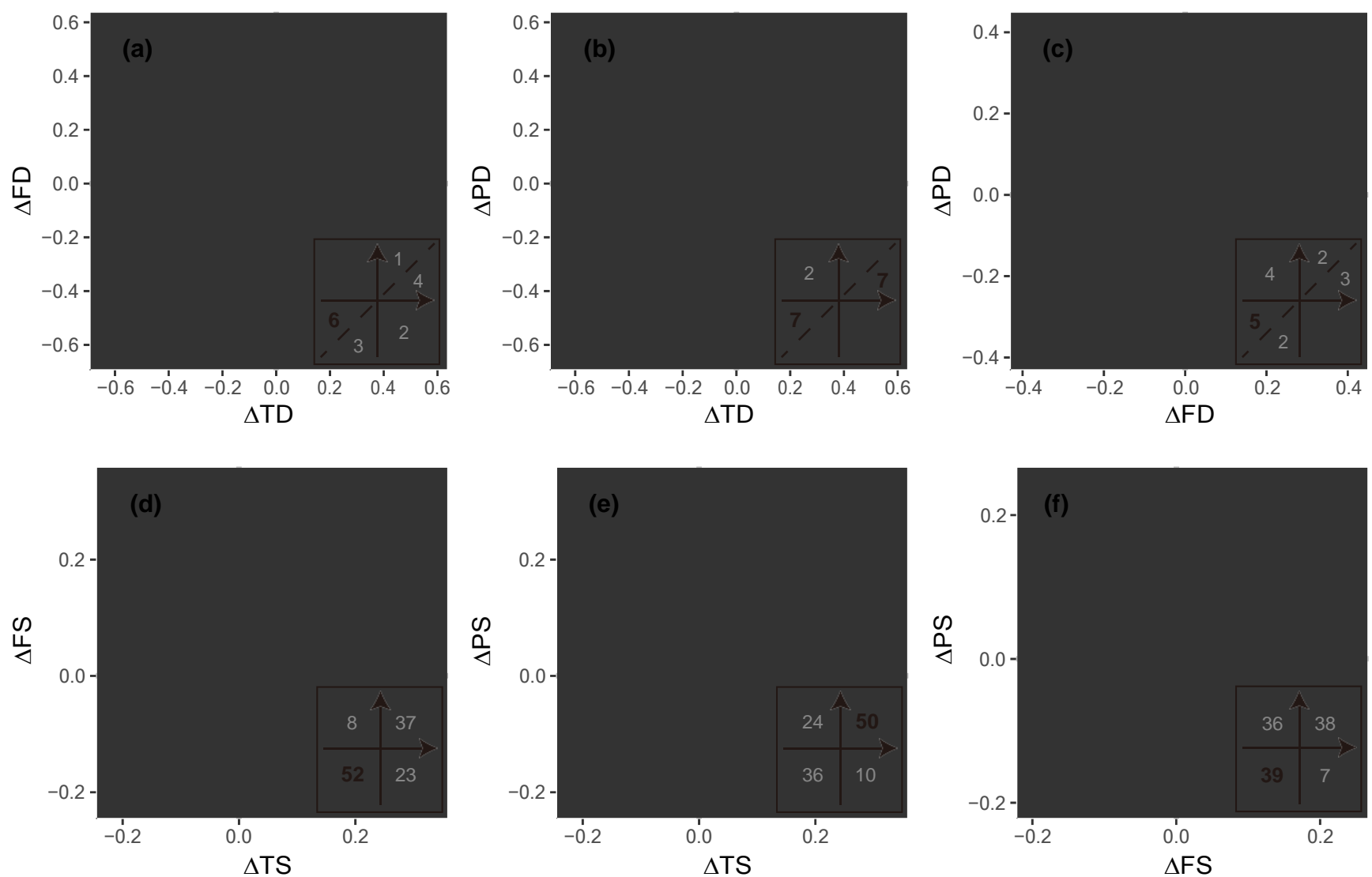

F I G U R E 4 Relationships between changes in taxonomic, functional, and phylogenetic diversity with the comparison between natural and agricultural habitats based on alpha $(a, b$, and $c)$ and beta diversity ( $d$, e, and f). Changes in alpha diversity were calculated as (agricultural diversity - natural diversity)/natural diversity, and changes in similarity as (agricultural similarity - natural similarity). The insets show the number of sites or site pairs within the different quadrants displayed in Figure 1, with the largest value being shown in bold for each inset. Blue solid lines indicate the slope of the relationship between any two kinds of changes. The dashed lines indicate the 1:1 line. All the slopes are significantly different from $1(p<.05)$ [Colour figure can be viewed at wileyonlinelibrary.com] 
the nematode community structure were only observed in natural habitats, and a greater difference in climate conditions could induce a higher dissimilarity in taxonomic, functional, and phylogenetic compositions (Table 1).

\subsection{Changes in community similarity and drivers of change}

We found that there were no significant changes in taxonomic similarity (Wilcoxon signed- rank test $p=.862$; Figure S9a), while the functional community composition was more dissimilar (differentiation; Wilcoxon signed-rank test $p<.001$; Figure S9b). The phylogenetic composition was more similar in agricultural sites (homogenization; Wilcoxon signed-rank test $p=.001$; Figure S9c).

We found that the initial community similarity was the most important predictor of changes in similarity, while communities with a higher initial similarity were less likely to become more taxonomically, functionally, or phylogenetically similar after habitat conversion (Table S6 and Figure S10). However, spatial distance, climate, and soil differences had no effects on the changes for all similarities. More than $55.0 \%$ of the variation was explained by full models, which included all the predictors of both the changes in taxonomic and phylogenetic similarities, while a relatively small proportion of the variation in the changes of functional similarity was accounted for (35.4\%; Table S6).

\subsection{Congruence among changes in taxonomic, functional, and phylogenetic diversity}

Although the three facets of diversity were highly correlated with each other at both the alpha and beta diversity levels (Tables S3 and S5), the changes in these facets were not congruent. A large change in TD was generally associated with a small change in both FD and PD (slopes significantly less than 1; Figure 4a-c). Among the seven sites that experienced increases in TD, most experienced smaller increases in FD (4) and PD (7). Of the nine sites that showed decreases in TD, declines were smaller for FD (6) and PD (7). In addition, comparison between changes in FD and PD showed that FD changed faster than PD. Similarly, we found relatively larger changes in taxonomic similarity than changes in functional or phylogenetic similarity, and in functional than in phylogenetic similarity among the assemblage pairs (slopes significantly less than 1 ; Figure 4d-f).

\section{4 | DISCUSSION}

Our study confirms that land-use conversion from natural to agricultural habitats affects the composition of soil biodiversity, as shown here for nematodes, in multiple diversity facets. Specifically, we found that functional community composition became more dissimilar in agricultural than in natural habitats, while phylogenetic composition became more similar. Unlike other studies, which found a loss of TD, FD, or PD in agricultural compared to natural habitats (Flynn et al., 2009; Frishkoff et al., 2014), we did not find such a pattern for soil nematodes. Thus, the hypotheses were not completely supported by our results, as the patterns and determinants of nema- tode diversity and composition differed between natural and agri- cultural soils and among diversity facets. Overall, unlike in natural habitats, the diversity and composition of soil nematodes in agricul- tural habitats did not vary with climate and soil conditions.

Agriculture is associated with lower diversities at low-latitude sites but with higher diversities at high-latitude sites compared to nearby natural habitats, resulting in no changes in overall alpha diversities. Since high diversity is often created by many rare and specialist taxa (Magurran \& Henderson, 2003; Mouillot et al., 2013) that are sensitive to environmental changes (Davies, Margules, \& Lawrence, 2004), we suggest that agricultural practices might lead to losses of these taxa in low- latitude sites. However, in contrast to low-latitude sites, the human-mediated dispersal of generalist taxa might increase the richness in high- latitude sites, because agricultural landscapes could be susceptible to species introduction when the biotic resistance is low (e.g., with low initial richness; Early et al., 2016; Levine, Adler, \& Yelenik, 2004). As the negative effects of agriculture on nematode communities are linked to warmer climates in low-latitude regions, nematode biodiversity might be increasingly lost under climate warming in agricultural soils. Nevertheless, the general hypothesis that land conversion would reduce nematode diversity is not supported here, as the effect of land conversion is latitude dependent.

Changes in TD were generally larger than changes in FD or PD, indicating that most of the lost/gained genera did not have unique functional roles or distinct phylogenetic distributions. Therefore, a profound level of functional and phylogenetic redundancy seems to be present in nematode assemblages, while the situation of larger changes in FD than in PD suggested that the functional and phylogenetic redundancies are not equivalent. We also detected an asynchrony of changes in taxonomic, functional, and phylogenetic similarity, which supports previous findings that changes in taxonomic composition provide limited information on ecosystem functioning and evolutionary history (Baiser \& Lockwood, 2011; Jarzyna \& Jetz, 2017; Villéger, Grenouillet, \& Brosse, 2013). The asynchronous changes between TD and FD in alpha diversity suggest that nematode communities experienced losses of functionally redundant taxa. Additionally, the decreases in both taxonomic and functional similarity could be due to the gains of different nematode genera with different traits and/or the losses of the same genera with similar traits. Therefore, the detected functional differentiation would mostly be caused by the losses of the same functionally redundant genera. Thus, unlike what we have hypothesized (i.e., agriculture would not affect the FD and $\beta F D$ of nematode communities due to functional redundancy among nematode taxa), the functional redundancy does not eliminate the effect of land conversion on FD and $\beta F D$. Similarly, gains and losses of phylogenetically redundant genera after land conversion in combination with 
the increases in both taxonomic and phylogenetic similarity indicate that the gains of the same phylogenetically redundant genera would mostly contribute to phylogenetic homogenization of soil nematode communities. Therefore, these different responses between functional and phylogenetic composition of nematode communities do not support the hypothesis that PD and $\beta P D$ show similar changes to FD and $\beta F D$.

A higher annual mean temperature or less temperature variation is associated with higher TD, FD, and PD in natural habitats. The crucial role played by temperature on alpha diversity was documented across a wide range of taxonomic groups (Hawkins et al., 2003), likely explained by differences in energy supply with high energy availability enabling higher numbers of co- existing taxa (Currie, 1991; Hawkins et al., 2003). We found sites with more similar climates that have similar nematode compositions in natural habitats. This finding is also supported across various taxonomic groups, including plants, birds, mammals, and soil organisms at large scales (Nielsen et al., 2014; Qian, Badgley, \& Fox, 2009; Qian \& Ricklefs, 2007; Tedersoo et al., 2014; Veech \& Crist, 2007; Wang et al., 2017). Unlike other studies that point out the important role of soil properties (e.g., SOC, TN, and pH) on soil fauna (Decaëns, 2010; Wu et al., 2011), we found a limited effect of any of the measured soil properties on the diversity of soil nematodes (only $\mathrm{pH}$ was negatively associated with FD and PD in natural habitats, indicating an environmental selection by $\mathrm{pH}$ on nematode functional and phylogenetic composition). The weak impact of soil properties on nematode communities may largely be explained by two reasons: (a) we used a large spatial scale (ranging from 22 to $40^{\circ} \mathrm{N}$ with a distance of over 2,600 km), at which taxon distribution may mainly be determined by macroclimate (Currie, 1991; Hawkins et al., 2003); and (b) the resolution of nematodes to genus level might overlook patterns and drivers only present at higher taxonomic resolution as commonly obtained through molecular sequencing tools for soil microorganisms (Delgado-Baquerizo et al., 2018; Tedersoo et al., 2014). Furthermore, we did not observe any effect of spatial distance on the composition of soil nematodes. This could be because environmental similarity (e.g., climate similarity) prompts greater taxon turnover directly (Nekola \& White, 1999; Soininen, McDonald, \& Hillebrand, 2007), while changes in community similarity at distances are slow among passively dispersed organisms (including nematodes) at large scales (Bahram et al., 2016; Finlay, 2002; Soininen et al., 2007).

A few limitations should be considered in this study. First, we identified nematodes at the genus level, whereas subtle differences among species might provide diversity information at a higher resolution. Species- level resolution is not possible in larger scale ecological studies using morphological identification (Geisen et al., 2018). Nevertheless, we expect that higher taxonomic resolution data, potentially obtained through developments in molecular approaches, will show similar results as found here, largely because the functional and phylogenetic relationships among the new units could be generally conserved at the genus or even family level (Geisen et al., 2018). Indeed, this higher resolution might strengthen our findings (i.e., different diversity patterns in natural and agricultural habitats, and asynchronous changes among multiple facets of diversity). Similar to other large-scale soil animal- centered studies (Nielsen et al., 2014; Wu et al., 2011), logistic constraints along the gradient of 2,600 km across China and our conservative site selection of comparable natural and agricultural sites reduced the sample size. We thus suggest that future studies should be conducted to evaluate our findings. Although the differences in vegetation composition and structure (especially among the natural sites) were not considered in this study, a recent study suggested that vegetation was not the main determinant of nematode communities at a global level (van den Hoogen et al., 2019). We focus our analysis on three functional traits that describe habitat preference and food acquisition of soil nematodes, because additional traits including morphological, physiological, and ecological traits are lacking for most nematodes (Bongers \& Bongers, 1998; Bongers \& Ferris, 1999; Ferris et al., 2001; Yeates et al., 1993), while the documented characteristics (e.g., c- $p$ value, body size) may vary among individuals and populations in response to local environmental conditions (Liu et al., 2015; Zhao \& Neher, 2013). However, in comparison to other soil organisms, nematodes can all reliably be classified into trophic feeding groups with different functional traits. Therefore, this study provides unique functional information on soil biodiversity.

Overall, this study sheds light on the ecological patterns and processes that determine soil nematode diversity under land-use changes. This will help us to understand and mitigate the effects of agriculture on belowground biodiversity by considering the interactions of land-use and environmental gradients, with the aim to maintain and enhance soil biodiversity and ultimately ecosystem functioning in soil.

\section{ACKNOWLEDG EMENTS}

We thank those persons who offered valuable help in the soil sampling and laboratory analysis, namely Jing Sun, Yong Zheng, Bo Yao, Chao Ma, Tongbin Zhu, Daoyuan Yu, Jiao Zhao, Jusong Huo and Chenchen Zhu. We also thank three anonymous reviewers for comments that improved the manuscript. Xiaoyun Chen is supported by National Natural Science Foundation of China (No. 41877056) and the Fundamental Research Funds for the Central Universities (No. KYYJ201702). Feng $\mathrm{Hu}$ is supported by the Special Fund for Agro-scientific Research in the Public Interest (No. 201503121) and China Agriculture Research System-Green Manure (No. CARS- 22- G-10). Stefan Geisen is supported by an NWO- VENI grant from the Netherlands Organisation for Scientific Research (No. 016. Veni.181.078). Manqiang Liu is supported by the National Key R\&D Program of China (No. 2016YFD0200305).

\section{DATA AVAIL ABILIT Y STATEMENT}

The raw data used in this study are available in the data repository Zenodo

(http://doi.org/10.5281/zenodo.3375277). 


\section{REFER EN CE S}

Bahram, M., Kohout, P., Anslan, S., Harend, H., Abarenkov, K., \& Tedersoo, L. (2016). Stochastic distribution of small soil eukaryotes resulting from high dispersal and drift in a local environment. The ISME Journal, 10, 885-896. https://doi.org/10.1038/ ismej.2015.164

Baiser, B., \& Lockwood, J. L. (2011). The relationship between functional and taxonomic homogenization. Global Ecology and Biogeography, 20, 134-144. https://doi.org/10.1111/j.1466- 8238.2010.00583.x

Bardgett, R. D., \& van der Putten, W. H. (2014). Belowground biodiversity and ecosystem functioning. Nature, 515, 505-511. https://doi. org/10.1038/nature13855

Baselga, A. (2010). Partitioning the turnover and nestedness components of beta diversity. Global Ecology and Biogeography, 19, 134-143. https://doi.org/10.1111/j.1466- 8238.2009.00490.x

Bivand, R. S., Pebesma, E., \& Gomez- Rubio, V. (2013). Applied spatial data analysis with $R$. New York, NY: Springer.

Blomberg, S. P., \& Garland, T. (2002). Tempo and mode in evolution: Phylogenetic inertia, adaptation and comparative methods. Journal of Evolutionary Biology, 15, 899-910. https://doi. org/10.1046/j.1420-9101.2002.00472.x

Bongers, T., \& Bongers, M. (1998). Functional diversity of nematodes. Applied Soil Ecology, 10, 239-251. https://doi.org/10.1016/ S0929-1393(98)00123- 1

Bongers, T., \& Ferris, H. (1999). Nematode community structure as a bioindicator in environmental monitoring. Trends in Ecology \& Evolution, 14, 224-228. https://doi.org/10.1016/S0169-5347(98)01583- 3

Bryant, J. A., Lamanna, C., Morlon, H., Kerkhoff, A. J., Enquist, B. J., \& Green, J. L. (2008). Microbes on mountainsides: Contrasting elevational patterns of bacterial and plant diversity. Proceedings of the National Academy of Sciences of the United States of America, 105, 11505-11511. https://doi.org/10.1073/pnas.0801920105

Chen, X., Daniell, T., Neilson, R., O'Flaherty, V., \& Griffiths, B. (2010). A comparison of molecular methods for monitoring soil nematodes and their use as biological indicators. European Journal of Soil Biology, 46, 319-324. https://doi.org/10.1016/j.ejsobi.2010.05.002

Clarke, K. R. (1993). Non-parametric multivariate analyses of changes in community structure. Australian Journal of Ecology, 18, 117-143. https://doi.org/10.1111/j.1442- 9993.1993.tb00438.x

Currie, D. J. (1991). Energy and large- scale patterns of animal- and plantspecies richness. The American Naturalist, 137, 27-49. https://doi. org/10.1086/285144

Davies, K. F., Margules, C. R., \& Lawrence, J. F. (2004). A synergistic effect puts rare, specialized species at greater risk of extinction. Ecology, 85, 265-271. https://doi.org/10.1890/03-0110

Decaëns, T. (2010). Macroecological patterns in soil communities. Global Ecology and Biogeography, 19, 287-302. https://doi.org/ 10.1111/j.1466- 8238.2009.00517.x

Delgado- Baquerizo, M., Oliverio, A. M., Brewer, T. E., Benavent- González, A., Eldridge, D. J., Bardgett, R. D., ... Fierer, N. (2018). A global atlas of the dominant bacteria found in soil. Science, 359, 320-325. https:// doi.org/10.1126/science.aap9516

Devictor, V., Julliard, R., Clavel, J., Jiguet, F., Lee, A., \& Couvet, D. (2008). Functional biotic homogenization of bird communities in disturbed landscapes. Global Ecology and Biogeography, 17, 252-261. https:// doi.org/10.1111/j.1466- 8238.2007.00364.x
Díaz, S., Fargione, J., Chapin, F. S. Iii, \& Tilman, D. (2006). Biodiversity loss threatens human well- being. PLoS Biology, 4, e277. https://doi. org/10.1371/journal.pbio.0040277

Dormann, C. F., McPherson, J. M., Araújo, M. B., Bivand, R., Bolliger, J., Carl, G., ... Wilson, R. (2007). Methods to account for spatial autocorrelation in the analysis of species distributional data: A review. Ecography, 30, 609-628. https://doi.org/10.1111/j.2007.0906- 7590.05171.x

Dray, S., \& Legendre, P. (2008). Testing the species traits-environment relationships: The fourth-corner problem revisited. Ecology, 89, 3400-3412. https://doi.org/10.1890/08-0349.1

Early, R., Bradley, B. A., Dukes, J. S., Lawler, J. J., Olden, J. D., Blumenthal, D. M., ... Tatem, A. J. (2016). Global threats from invasive alien species in the twenty- first century and national response capacities. Nature Communications, 7, 12485. https://doi.org/10.1038/ncomms 12485

Faith, D. P. (1992). Conservation evaluation and phylogenetic diversity. Biological Conservation, 61, 1-10. https://doi.org/10.1016/ 0006-3207(92)91201- 3

Ferris, H. (2010). Form and function: Metabolic footprints of nematodes in the soil food web. European Journal of Soil Biology, 46, 97-104. https://doi.org/10.1016/j.ejsobi.2010.01.003

Ferris, H., Bongers, T., \& de Goede, R. G. M. (2001). A framework for soil food web diagnostics: Extension of the nematode faunal analysis concept. Applied Soil Ecology, 18, 13-29. https://doi.org/10.1016/ S0929-1393(01)00152-4

Finlay, B. J. (2002). Global dispersal of free- living microbial eukaryote species. Science, 296, 1061-1063. https://doi.org/10.1126/scien ce. 1070710

Floyd, R., Abebe, E., Papert, A., \& Blaxter, M. (2002). Molecular barcodes for soil nematode identification. Molecular Ecology, 11, 839-850. https://doi.org/10.1046/j.1365-294X.2002.01485.x

Flynn, D. F. B., Gogol-Prokurat, M., Nogeire, T., Molinari, N., Richers, B. T., Lin, B. B., ... DeClerck, F. (2009). Loss of functional diversity under land use intensification across multiple taxa. Ecology Letters, 12, 2233. https://doi.org/10.1111/j.1461-0248.2008.01255.x

Freckman, D. W., \& Ettema, C. H. (1993). Assessing nematode communities in agroecosystems of varying human intervention. Agriculture, Ecosystems \& Environment, 45, 239-261. https://doi. org/10.1016/0167-8809(93)90074- Y

Frishkoff, L. O., Karp, D. S., M'Gonigle, L. K., Mendenhall, C. D., Zook, J., Kremen, C., ... Daily, G. C. (2014). Loss of avian phylogenetic diversity in neotropical agricultural systems. Science, 345, 1343-1346. https:// doi.org/10.1126/science. 1254610

Gee, G. W., \& Or, D. (2002). Particle- size analysis. In J. Dane \& G. Topp (Eds.), Methods of soil analysis: Part 4 physical methods (pp. 255-293). Madison, WI: Soil Science Society of America.

Geisen, S., Snoek, L. B., ten Hooven, F. C., Duyts, H., Kostenko, O., Bloem, J., ... van der Putten, W. H. (2018). Integrating quantitative morphological and qualitative molecular methods to analyse soil nematode community responses to plant range expansion. Methods in Ecology and Evolution, 9, 1366-1378. https://doi. org/10.1111/2041- 210X.12999

Goslee, S. C., \& Urban, D. L. (2007). The ecodist package for dissimilaritybased analysis of ecological data. Journal of Statistical Software, 22, 119. http://doi.org/10.18637/jss.v022.i07

Gossner, M. M., Lewinsohn, T. M., Kahl, T., Grassein, F., Boch, S., Prati, D., ... Allan, E. (2016). Land- use intensification causes multitrophic homogenization of grassland communities. Nature, 540, 266-269. https ://doi.org/10.1038/nature20575

Grafen, A. (1989). The phylogenetic regression. Philosophical Transactions of the Royal Society of London. Series B, Biological Sciences, 326, 119157. https://doi.org/10.1098/rstb.1989.0106

Graham, C. H., \& Fine, P. V. A. (2008). Phylogenetic beta diversity: Linking ecological and evolutionary processes across space in time. Ecology Letters, 11, 1265-1277. https://doi. org/10.1111/j.1461-0248.2008.01256.x 
Hawkins, B. A., Field, R., Cornell, H. V., Currie, D. J., Guégan, J.- F., Kaufman, D. M., ... Turner, J. R. G. (2003). Energy, water, and broadscale geographic patterns of species richness. Ecology, 84, 31053117. https://doi.org/10.1890/03- 8006

Hinchliff, C. E., Smith, S. A., Allman, J. F., Burleigh, J. G., Chaudhary, R., Coghill, L. M., ... Cranston, K. A. (2015). Synthesis of phylogeny and taxonomy into a comprehensive tree of life. Proceedings of the National Academy of Sciences of the United States of America, 112, 12764-12769. https://doi.org/10.1073/pnas.1423041112

Jarzyna, M. A., \& Jetz, W. (2016). Detecting the multiple facets of biodiversity. Trends in Ecology \& Evolution, 31, 527-538. https://doi. org/10.1016/j.tree.2016.04.002

Jarzyna, M. A., \& Jetz, W. (2017). A near half- century of temporal change in different facets of avian diversity. Global Change Biology, 23, 29993011. https://doi.org/10.1111/gcb.13571

Karp, D. S., Rominger, A. J., Zook, J., Ranganathan, J., Ehrlich, P. R., \& Daily, G. C. (2012). Intensive agriculture erodes $\beta$-diversity at large scales. Ecology Letters, 15, 963-970. https://doi. org/10.1111/j.1461- 0248.2012.01815.x

Legendre, P., Galzin, R., \& Harmelin- Vivien, M. L. (1997). Relating behavior to habitat: Solutions to the fourth-corner problem. Ecology, 78, 547-562. https://doi.org/10.2307/2266029

Levine, J. M., Adler, P. B., \& Yelenik, S. G. (2004). A meta- analysis of biotic resistance to exotic plant invasions. Ecology Letters, 7, 975-989. https ://doi.org/10.1111/j.1461-0248.2004.00657.x

Li, J.- T., Li, S.- P., Chen, Y.- J., Jia, P. U., Hua, Z.- S., Wang, S.- L., ... Shu, W.- S. (2014). Phylogenetic structures of soil nematode communities alonga successional gradient in an unreclaimed copper mine tailings site. Soil Biology \& Biochemistry, 77, 179-186. https://doi.org/10.1016/j.soilbio.2014.06.007

Li, P., Guan, Q., Wu, M., Kang, G., Liu, M., Li, H., ... Jiao, J. (2017). Investigation of temporal and spatial variability of soil nutrients in double cropping area of the upland. Chinese Journal of Soil Science, 48, 380-386. (in Chinese)

Li, P., Shi, K., Wang, Y., Kong, D., Liu, T., Jiao, J., ... Hu, F. (2019). Soil quality assessment of wheat- maize cropping system with different productivities in China: Establishing a minimum data set. Soil and Tillage Research, 190, 31-40. https://doi.org/10.1016/j.still.2019.02.019

Lichstein, J. W. (2007). Multiple regression on distance matrices: A multi- variate spatial analysis tool. Plant Ecology, 188, 117-131. https://doi.org/10.1007/s11258- 006- 9126- 3

Liu, M., Chen, X., Qin, J., Wang, D., Griffiths, B., \& Hu, F. (2008). A sequential extraction procedure reveals that water management affects soil nematode communities in paddy fields. Applied Soil Ecology, 40, 250-259. https://doi.org/10.1016/j.apsoil.2008.05.001

Liu, T., Guo, R., Ran, W., Whalen, J. K., \& Li, H. (2015). Body size is a sensitive trait-based indicator of soil nematode community response to fertilization in rice and wheat agroecosystems. Soil Biology \& Biochemistry, 88, 275-281. https://doi.org/10.1016/j.soilbio.2015.05.027

Magurran, A. E., \& Henderson, P. A. (2003). Explaining the excess of rare species in natural species abundance distributions. Nature, 422, 714716. https://doi.org/10.1038/nature01547

McGill, B. J., Dornelas, M., Gotelli, N. J., \& Magurran, A. E. (2015). Fifteen forms of biodiversity trend in the Anthropocene. Trends in Ecology \& Evolution, 30, 104-113. https://doi.org/10.1016/j.tree.2014.11.006

Meng, E. C. H., Hu, R., Shi, X., \& Zhang, S. (2006). Maize in China: Production systems, constraints, and research priorities. Mexico, DF: CIMMYT.

Michonneau, F., Brown, J. W., \& Winter, D. J. (2016). rotl: An R package to interact with the Open Tree of Life data. Methods in Ecology and Evolution, 7, 1476-1481. https://doi.org/10.1111/2041- 210x.12593

Montgomery, D. R. (2007). Soil erosion and agricultural sustainability. Proceedings of the National Academy of Sciences of the United States of America, 104, 13268-13272. https://doi.org/10.1073/pnas.06115 08104
Mori, A. S., Isbell, F., \& Seidl, R. (2018). $\beta$ - Diversity, community assembly, and ecosystem functioning. Trends in Ecology \& Evolution, 33, 549564. https://doi.org/10.1016/j.tree.2018.04.012

Mouchet, M. A., Villéger, S., Mason, N. W. H., \& Mouillot, D. (2010). Functional diversity measures: An overview of their redundancy and their ability to discriminate community assembly rules. Functional Ecology, 24, 867-876. https://doi. org/10.1111/j.1365-2435.2010.01695.x

Mouillot, D., Bellwood, D. R., Baraloto, C., Chave, J., Galzin, R., HarmelinVivien, M., ... Thuiller, W. (2013). Rare species support vulnerable functions in high- diversity ecosystems. PLoS Biology, 11, e1001569. https://doi.org/10.1371/journal.pbio.1001569

Mulder, C., \& Maas, R. (2017). Unifying the functional diversity in natural and cultivated soils using the overall body-mass distribution of nematodes. BMC Ecology, 17, 36-49. https://doi.org/10.1186/ s12898- 017-0145- 9

Neher, D. A. (2010). Ecology of plant and free- living nematodes in natural and agricultural soil. Annual Review of Phytopathology, 48, 371-394. https://doi.org/10.1146/annurev- phyto-073009-114439

Neher, D. A., Peck, S. L., Rawlings, J. O., \& Campbell, C. L. (1995). Measures of nematode community structure and sources of variability among and within agricultural fields. Plant and Soil, 170, 167-181. https://doi.org/10.1007/BF02183065

Nekola, J. C., \& White, P. S. (1999). The distance decay of similarity in biogeography and ecology. Journal of Biogeography, 26, 867-878. https ://doi.org/10.1046/j.1365- 2699.1999.00305.x

Nielsen, U. N., Ayres, E., Wall, D. H., Li, G., Bardgett, R. D., Wu, T., \& Garey, J. R. (2014). Global-scale patterns of assemblage structure of soil nematodes in relation to climate and ecosystem properties. Global Ecology and Biogeography, 23, 968-978. https://doi. org/10.1111/geb.12177

Nowakowski, A. J., Frishkoff, L. O., Thompson, M. E., Smith, T. M., \& Todd, B. D. (2018). Phylogenetic homogenization of amphibian assemblages in human- altered habitats across the globe. Proceedings of the National Academy of Sciences of the United States of America, 115, E3454-E3462. https://doi.org/10.1073/pnas.1714891115

Paradis, E., Claude, J., \& Strimmer, K. (2004). Ape: Analyses of phylogenetics and evolution in R language. Bioinformatics, 20, 289-290. https ://doi.org/10.1093/bioinformatics/btg412

Paul, E. A. (2015). Soil microbiology, ecology and biochemistry. London, UK: Academic Press.

Petchey, O. L., \& Gaston, K. J. (2002). Functional diversity (FD), species richness and community composition. Ecology Letters, 5, 402-411. https://doi.org/10.1046/j.1461-0248.2002.00339.x

Pickett, S. T. (1989). Space- for-time substitution as an alternative to long- term studies. In G. E. Likens (Ed.), Long-term studies in ecology: Approaches and alternatives (pp. 110-135). New York, NY: Springer.

Podani, J., \& Schmera, D. (2006). On dendrogram-based measures of functional diversity. Oikos, 115, 179-185. https://doi. org/10.1111/j.2006.0030-1299.15048.x

Ponisio, L. C., M'Gonigle, L. K., \& Kremen, C. (2016). On- farm habitat restoration counters biotic homogenization in intensively managed agriculture. Global Change Biology, 22, 704-715. https://doi.org/10.1111/ gcb. 13117

Postma-Blaauw, M. B., de Goede, R. G. M., Bloem, J., Faber, J. H., \& Brussaard, L. (2010). Soil biota community structure and abundance under agricultural intensification and extensification. Ecology, 91, 460-473. https://doi.org/10.1890/09-0666.1

Qian, H., Badgley, C., \& Fox, D. L. (2009). The latitudinal gradient of beta diversity in relation to climate and topography for mammals in North America. Global Ecology and Biogeography, 18, 111-122. https://doi. org/10.1111/j.1466- 8238.2008.00415.x

Qian, H., \& Ricklefs, R. E. (2007). A latitudinal gradient in large- scale beta diversity for vascular plants in North America. Ecology Letters, 10, 737-744. https://doi.org/10.1111/j.1461- 0248.2007.01066.x 
R Core Team. (2016). R: A language and environment for statistical computing. Vienna, Austria: R Foundation for Statistical Computing.

Schleuter, D., Daufresne, M., Massol, F., \& Argillier, C. (2010). A user's guide to functional diversity indices. Ecological Monographs, 80, 469484. https://doi.org/10.1890/08- 2225.1

Socolar, J. B., Gilroy, J. J., Kunin, W. E., \& Edwards, D. P. (2016). How should beta- diversity inform biodiversity conservation? Trends in Ecology \& Evolution, 31, 67-80. https://doi.org/10.1016/j.tree.2015.11.005

Soininen, J., Mcdonald, R., \& Hillebrand, H. (2007). The distance decay of similarity in ecological communities. Ecography, 30, 3-12. https://doi. org/10.1111/j.0906- 7590.2007.04817.x

Sol, D., Bartomeus, I., González-Lagos, C., \& Pavoine, S. (2017). Urbanisation and the loss of phylogenetic diversity in birds. Ecology Letters, 20, 721-729. https://doi.org/10.1111/ele.12769

Solar, R. R. D. C., Barlow, J., Ferreira, J., Berenguer, E., Lees, A. C. Thomson, J. R., ... Gardner, T. A. (2015). How pervasive is biotic homogenization in human- modified tropical forest landscapes? Ecology Letters, 18, 1108-1118. https://doi.org/10.1111/ele.12494

Swenson, N. G. (2011). Phylogenetic beta diversity metrics, trait evolution and inferring the functional beta diversity of communities. PLoS ONE, 6, e21264. https://doi.org/10.1371/journal.pone.0021264

Tedersoo, L., Bahram, M., Polme, S., Koljalg, U., Yorou, N. S., Wijesundera, R., ... Abarenkov, K. (2014). Global diversity and geography of soil fungi. Science, 346, 1256688. https://doi.org/10.1126/science.1256688

Tilman, D., Balzer, C., Hill, J., \& Befort, B. L. (2011). Global food demand and the sustainable intensification of agriculture. Proceedings of the National Academy of Sciences of the United States of America, 108, 20260-20264. https://doi.org/10.1073/pnas.1116437108

van den Hoogen, J., Geisen, S., Routh, D., Ferris, H., Traunspurger, W., Wardle, D. A., ... Crowther, T. W. (2019). Soil nematode abundance and functional group composition at a global scale. Nature, 572, 194 198. https://doi.org/10.1038/s41586- 019-1418- 6

Veech, J. A., \& Crist, T. O. (2007). Habitat and climate heterogeneity maintain beta-diversity of birds among landscapes within ecoregions. Global Ecology and Biogeography, 16, 650-656. https://doi. org/10.1111/j.1466-8238.2007.00315.x

Villéger, S., Grenouillet, G., \& Brosse, S. (2013). Decomposing functional $\beta$-diversity reveals that low functional $\beta$-diversity is driven by low functional turnover in European fish assemblages. Global Ecology and Biogeography, 22, 671-681. https://doi.org/10.1111/geb.12021

Villéger, S., Mason, N. W. H., \& Mouillot, D. (2008). New multidimensional functional diversity indices for a multifaceted framework in functional ecology. Ecology, 89, 2290-2301. https://doi.org/10.1890/07- 1206.1
Wang, X.- B., Lü, X.- T., Yao, J., Wang, Z.-W., Deng, Y. E., Cheng, W.-X., ... Han, X.- G. (2017). Habitat- specific patterns and drivers of bacterial $\beta$-diversity in China's drylands. The ISME Journal, 11, 13451358.https://doi.org/10.1038/ismej.2017.11

Wardle, D. A., Bardgett, R. D., Klironomos, J. N., Setälä, H., van der Putten, W. H., \& Wall, D. H. (2004). Ecological linkages between aboveground and belowground biota. Science, 304, 1629-1633. https:// doi.org/10.1126/science.1094875

Whittaker, R. H. (1972). Evolution and measurement of species diversity. Taxon, 21, 213-251. https://doi.org/10.2307/1218190

Winter, M., Devictor, V., \& Schweiger, O. (2013). Phylogenetic diversity and nature conservation: Where are we? Trends in Ecology \& Evolution, 28, 199-204. https://doi.org/10.1016/j.tree.2012.10.015

Wu, T., Ayres, E., Bardgett, R. D., Wall, D. H., \& Garey, J. R. (2011). Molecular study of worldwide distribution and diversity of soil animals. Proceedings of the National Academy of Sciences of the United States of America, 108, 17720-17725. https://doi.org/10.1073/ pnas. 1103824108

Yeates, G. W. (2003). Nematodes as soil indicators: Functional and biodi- versity aspects. Biology and Fertility of Soils, 37, 199-210.

Yeates, G. W., Bongers, T., de Goede, R. G. M., Freckman, D. W., \& Georgieva, S. S. (1993). Feeding habits in soil nematode families and genera - An outline for soil ecologists. Journal of Nematology, 25, 315-331.

Zhao, J., \& Neher, D. A. (2013). Soil nematode genera that predict specific types of disturbance. Applied Soil Ecology, 64, 135-141. https://doi. org/10.1016/j.apsoil.2012.11.008 